\title{
Are Desires Beliefs about Normative Reasons?
}

\author{
Avery Archer \\ George Washington University
}

\begin{abstract}
There has been an ongoing debate about whether desires are beliefs. Call the claim that they are the desire-as-belief thesis $(D A B)$. This paper sets out to impugn the two versions of $\mathrm{DAB}$ that have enjoyed the most support in the philosophical literature: the guise of the good and the guise of reasons accounts. According to the guise of the good version of $\mathrm{DAB}$, the desire to $\varphi$ is identical to the belief that $\varphi$ is good. According to the guise of reasons version of $\mathrm{DAB}$, the desire to $\varphi$ is identical to the belief that one has a normative reason to $\varphi$. My paper presents a pair of objections to DAB: the first specifically targets the guise of reasons account defended by Alex Gregory, while the second aims to undermine DAB more generally.
\end{abstract}

KEYWORDS: Guise of Reasons, Guise of the Good, Desires, Beliefs, Normative Reasons

\section{Introduction}

Since the late 1980's, there has been an ongoing debate about whether desires are beliefs. Call the claim that they are the desire-as-belief thesis (henceforth, $D A B$ ). The most recent defense of DAB is that offered in a series of essays by Alex Gregory $(2013,2017,2018)$, who argues that the desire to $\varphi$ is identical to the belief that one has a normative reason to $\varphi .{ }^{1}$ Call Gregory's thesis the guise of reasons formulation of $D A B$ (henceforth, $D A B^{G R}$ ). $D A B^{G R}$ is an alternative to the more traditional guise of the good formulation of $D A B$ (henceforth, $D A B^{G G}$ ), which holds that desiring to $\varphi$ is identical to the belief that $\varphi$ is good. ${ }^{2}$ Both versions of DAB stand in contrast to their more modest desireas-appearance (henceforth, DAA) counterparts, which claim that desiring to $\varphi$ involves an appearance of $\varphi$ as good (i.e., the guise of the good formulation of DAA) or that desiring to $\varphi$ involves an appearance of there being a normative reason to $\varphi$ (i.e., the guise of reasons formulation of DAA).

While I remain convinced that both versions of DAA are superior to both versions of DAB, I will not be attempting to offer a defense of either version of DAA here. ${ }^{3}$ Instead, my focus will be on impugning DAB. Specifically, I shall argue that both $\mathrm{DAB}^{\mathrm{GR}}$ and $\mathrm{DAB}^{\mathrm{GG}}$ display weaknesses that warrant their rejection. To this end, I will be advancing two independent lines of criticism. The first specifically targets $\mathrm{DAB}^{\mathrm{GR}}$ by offering a counterexample to the claim that believing one has a reason to $\varphi$ entails desiring to $\varphi$. If successful, this will establish the falsity of the right-to-left direction of the biconditional implicated by the identification of a desire with a belief about normative reasons. My second objection targets both $\mathrm{DAB}^{\mathrm{GR}}$ and $\mathrm{DAB} \mathrm{BG}^{\mathrm{GG}}$ and seeks to establish the falsity of the left-to-right direction of the biconditional implicated by the identification of a desire with a belief. When combined, I take the pair of objections limned in this paper to show that both $\mathrm{DAB}^{\mathrm{GR}}$ and $\mathrm{DAB} \mathrm{BG}^{\mathrm{G}}$ are false. 


\section{A Sufficient Condition for Belief}

Before delving into my objections to $\mathrm{DAB}{ }^{\mathrm{GR}}$, I wish to establish a sufficient condition for an agent to believe $\mathbf{P}$. (As we shall soon see, this will play an important role in my first objection to $\mathrm{DAB}^{\mathrm{GR}}$.) To this end, I take being completely sure that $\mathbf{P}$ to be a sufficient condition for believing $\mathbf{P}$. Call this the certainty sufficiency thesis. Two points of clarification about the certainty sufficiency thesis are in order. Firstly, the notion of certainty currently at play is psychological, not evidential. To say that an agent is completely sure that $\mathbf{P}$, as I shall be using the expression, means that they have the maximum amount of confidence or conviction that $\mathbf{P}$ is true. However, being completely sure that $\mathbf{P}$ does not mean that an agent possesses conclusive evidence that $\mathbf{P}$. This is an important disambiguation to make because we want to allow for the possibility of an agent having unjustified or unwarranted beliefs, even in cases in which the agent feels completely sure that $\mathbf{P}$. By distinguishing between being completely sure that $\mathbf{P}$ and having conclusive evidence that $\mathbf{P}$, we allow for the possibility of a certain kind of irrationality-i.e., displaying a level of certainty in a proposition that is not warranted by one's available evidence. ${ }^{4}$ This brings us to my second point about the certainty sufficiency thesis; namely, it is meant to be a sufficient condition for having a belief simpliciter, not a sufficient condition for having a justified or warranted belief.

I take the truth of the certainty sufficiency thesis to be established by the fact that it would be absurd to say that someone is completely sure that $\mathbf{P}$ but that they fail to believe that $\mathbf{P}$. That this is so is illustrated by the fact that the following declaration sounds absurd in a manner reminiscent of a Moorean paradox:

(A) "I am completely sure that $\mathbf{P}$ but I do not believe that $\mathbf{P}$ ".

However, unlike genuine examples of the Moorean paradox, the absurdity attached to denying the certainty sufficiency thesis is equally present in the third person:

(B) "Alex is completely sure that $\mathbf{P}$ but he does not believe that $\mathbf{P}$ ".

I submit that the absurdity of (A) and (B) is rooted in the fact that being completely sure that $\mathbf{P}$ (i.e., displaying the maximal degree of psychological conviction that $\mathbf{P}$ is true) entails the belief that $\mathbf{P}$. With our sufficient condition for believing $\mathbf{P}$ in place, I now turn to my first objection to $\mathrm{DAB}^{\mathrm{GR}}$.

\section{The Psychopathy Objection}

According to Gregory, desiring to $\varphi$ is both necessary and sufficient for believing that one has a normative reason to $\varphi$. He puts the point as follows:

First, imagine that I desire to read Asimov's Foundation. According to DAB, this is just the same as my believing that I have a reason to read Asimov's Foundation. (Perhaps I think it will be fun.) Second, imagine that I believe I have a reason to buy a new scarf 
today. (I've lost the old one.) According to DAB, this is just the same as my desiring to buy a new scarf today. (2017, p. 201)

While the version of $D A B^{G R}$ defended by Gregory involves a biconditional claim, we can imagine a weaker version of $\mathrm{DAB}{ }^{\mathrm{GR}}$ according to which all desires are beliefs about normative reasons to act, but not all beliefs about normative reasons to act are desires. Since my first objection to DAB ${ }^{\mathrm{GR}}$ will target the claim that believing one has a normative reason to $\varphi$ is sufficient for desiring to $\varphi$, it fails to impugn the weaker thesis, which only involves a necessity claim. However, my second objection to $\mathrm{DAB}^{\mathrm{GR}}$ will target the claim that believing one has a normative reason to $\varphi$ is a necessary condition for desiring to $\varphi$. Combined, the pair of objections advanced in this paper will show that both directions of the biconditional implicated by DAB ${ }^{\mathrm{GR}}$ are false.

My first objection to $\mathrm{DAB}^{\mathrm{GR}}$ will involve the psychiatric notion of psychopathy. Although the terms psychopath and sociopath are popularly used interchangeably, within the psychiatric literature, the terms are standardly used to refer to psychological conditions that differ in at least three important ways. First, psychopathy is taken to have a strong hereditary or genetic component while sociopathy is taken to be due primarily to environmental factors. Anthony Walsh and Huei-Hsia Wu put the point as follows:

$[P]$ sychopaths are a stable proportion of any population, can be from any segment of society, may constitute a distinct taxonomical class forged by frequency-dependent natural selection, and that the muting of the social emotions is the proximate mechanism that enables psychopaths to pursue their self-centered goals without feeling the pangs of guilt. Sociopaths are more the products of adverse environmental experiences that affect autonomic nervous system and neurological development that may lead to physiological responses similar to those of psychopaths. (Walsh \& Wu 2008, p. 135).

Second, psychopaths tend to display a more extreme and pervasive lack of empathy, guilt and remorse than sociopaths. Clinical and forensic psychologist, Kelly McAleer, puts the point as follows:

The capacity to feel attachment and empathy towards another and to feel guilt and shame after doing something wrong is not associated with psychopathy; however it is suggested that sociopaths can emotionally attach to others, and feel badly when they hurt those individuals that they are attached to (McAleer 2010).

Third, while most sociopaths display a lack of self-control and forethought, psychopaths tend to display a high level of self-regulation and calculation. Moreover, psychopaths typically display no obvious deficits in logical reasoning or critical thinking. McAleer (2010) elaborates on this point:

The psychopath is callous, yet charming. He or she will con and manipulate others with charisma and intimidation and can effectively mimic feelings to present as "normal" to society. The psychopath is organized in their criminal thinking and behavior, and can 
maintain good emotional and physical control, displaying little to no emotional or autonomic arousal, even under situations that most would find threatening or horrifying. The psychopath is keenly aware that what he or she is doing is wrong, but does not care (Ibid).

Given the constantly evolving nature of psychiatric classifications, I do not presume that the particular ways of distinguishing between psychopaths and sociopaths adumbrated above are the final word on the matter. What interests me is not the distinction itself but rather the kind of agent the label of psychopath is meant to pick out. Specifically, the psychopath is someone who displays an extreme lack of what I shall call the moral emotions, such as feelings of empathy, guilt, and remorse. In non-psychopaths, the moral emotions play an important, and perhaps even essential, role in motivating pro-social behavior, including conformity to moral norms. However, the psychopath's lack of these moral emotions may leave them entirely unmotivated to engage in pro-social behavior or avoid certain anti-social behavior. Moreover, the lack of moral emotions displayed by psychopaths need not diminish their ability to identify socially prescribed moral norms as such. Insofar as they display no obvious deficits in logical reasoning and critical thinking - and in some cases may even display a superior ability to think critically than nonpsychopaths - a psychopath may still recognize that there are normative reasons against certain anti-social behaviors. Given the large body of evidence that agents fitting this description make up a small but non-zero part of the human population, the following scenario appears to be a live possibility:

\section{Psychopathic Sam:}

Sam has been clinically diagnosed with psychopathy, displays an extreme lack of empathy and guilt, and derives enjoyment from torturing small animals. He believes torturing animals is morally prohibited, but he has no desire to bring his conduct in line with moral requirements and feels no guilt about failing to do so. In order to fulfil his university's general education requirement, Sam enrolls in a metaethics course. The arguments he encounters during the course persuade him that the fact that something is morally prohibited is sufficient for one to have a normative reason to do that thing. Indeed, by the end of the semester, Sam is completely sure that he has a normative reason to stop torturing animals for fun. However, while the arguments he encountered in class were sufficient to alter Sam's theoretical commitments they were powerless to generate the empathy needed to alter Sam's desires. In short, Sam believes that he has a normative reason to refrain from torturing animals (based on the persuasive arguments presented in his metaethics class) but he has no desire or intention to stop.

The description of Sam just offered is consistent with the standard conception of psychopathy found in the psychiatric literature. As we already noted, one of the hallmarks of psychopathy is that the agent in question displays no obvious deficits in their reasoning ability. This means that the fact that Sam lacks the ability to experience empathy and guilt does not preclude him from successfully following a line of argument or validly deducing a conclusion from a set of premises. Hence, it is entirely conceivable that Sam may arrive at the belief that he has a normative reason 
not to torture animals, based on the premise that doing so is morally prohibited and the further premise that an agent has a normative reason to refrain from doing what is morally prohibited. Indeed, we can stipulate that Sam is entirely convinced by the arguments presented in his metaethics class, such that he is completely sure that he has a normative reason to stop torturing animals. Given the certainty sufficiency thesis, it follows that Sam believes he has a normative reason to stop torturing animals. It is also entirely conceivable that Sam's extreme and pathological lack of empathy, combined with the pleasure he derives from torturing animals, may be sufficient to causally prevent him from ever forming the desire to stop torturing animals. The upshot is that Psychopathic Sam represents a case in which an agent has no desire to do what they believe they have normative reason to do.

One potential line of reply to the Psychopathic Sam objection would be to argue that insofar as Sam lacks what I have been calling moral emotions, he could not have genuine moral beliefs. On the present suggestion, moral beliefs are not merely beliefs with a certain content-i.e., propositions about particular courses of action being right or wrong. Rather, moral beliefs involve a combination of a belief and a certain emotional profile; one that implicates one or more moral emotions. Insofar as Sam lacks the relevant emotional profile, he also lacks moral beliefs. This appears to allow the defender of $\mathrm{DAB}^{\mathrm{GR}}$ to claim that since Sam lacks the relevant moral belief, the fact that he has no desire to refrain from torturing animals is not a counterexample to $\mathrm{DAB}^{\mathrm{GR}}$. Significantly, the present line of reply is unable to preserve the version of $\mathrm{DAB}^{\mathrm{GR}}$ defended by Gregory. This is because Gregory identifies the desire to $\varphi$ with simply believing that one has a normative reason to $\varphi$, whereas the view currently under consideration acknowledges that moral beliefs are something more than a mere belief given that they require the presence of certain emotional states. Even so, we may revise Gregory's view so that the desire to $\varphi$ is identified with the moral belief that one has a normative reason to $\varphi$. On the present suggestion, desires are not identical to beliefs about one's normative reasons to act, simpliciter, but rather to a certain subset of one's beliefs about one's normative reasons to act-namely, those accompanied by one or more moral emotions. Call this revised version of Gregory's account desire-as-moral-belief (henceforth, $D A M B$ ).

Unfortunately, DAMB has the unhappy implication that an agent who lacked all moral emotions - such as empathy, guilt, and remorse-would ipso facto lack any desires. This is an unhappy result for at least two reasons. First, it implies that Sam could not desire to torture animals simply because he lacks the ability to empathize with others. But clearly, a psychopath's inability to empathize does not preclude them from having anti-social or immoral desires, such as the desire to torture animals. Second, it is no part of our concept of desire that they be necessarily tied to emotions like empathy, guilt, and remorse. Indeed, it is not obvious that our concept of a desire requires that the desiring agent experience any emotions at all. Moreover, even if we did think it would be impossible to have desires if one did not experience at least some emotions, the moral emotions represent only a very narrow subset of the emotions an agent may experience. They exclude, for example, amoral and/or immoral emotions like frustration, resentment, and hatred. However, such amoral and/or immoral emotions seem to play no less of a role in generating desire than the moral emotions. Hence, even if one did think all desires are accompanied by some kind of emotion, there is nothing in our concept of a desire that would prompt us to restrict the emotions in question to the moral emotions. Moreover, while our 
imagined psychopath lacks any moral emotions, he does not lack all amoral and/or immoral emotions. There is therefore no obvious obstacle to his having the desire to, say, torture animals. The upshot is that DAMB's implication that an agent who lacks all moral emotions would ipso facto lack any desires is unsound.

It should also be emphasized that the appeal to moral beliefs is not essential to the Psychopathic Sam example. We may replace Sam's belief that torturing animals is morally prohibited with the belief that torturing animals is socially frowned upon without reducing the efficacy of my argument. ${ }^{5}$ Unlike the belief that a certain act is morally prohibited (which, it is alleged, requires the possession of moral emotions), the belief that an act is socially frowned upon involves a straightforward factual claim. As such, it should be relatively uncontroversial that it is something Sam could believe, irrespective of his emotional profile. We are then free to amend the rest of the example accordingly. Instead of being persuaded that an act being morally prohibited is sufficient for having a normative reason to refrain from performing it, we can suppose that Sam comes to believe that the fact that an act is socially frowned upon is sufficient for having a normative reason to refrain from performing it.

According to the present suggestion, we can imagine Sam being convinced (whether based on sound reasoning or not) that the fact that an act is socially frowned upon gives him a reason to refrain from performing it, and then inferring that he has a normative reason to stop torturing animals from the fact that torturing animals is socially frowned upon. Indeed, we may stipulate that Sam is completely sure (whether justifiably or not) that he has a normative reason to stop torturing animals, based on the aforementioned piece of reasoning. It follows from the certainty sufficiency thesis that Sam believes that he has a normative reason to refrain from torturing animals. Furthermore, it is also conceivable that-given his lack of moral emotions and the enjoyment he derives from animal torture-Sam may continue to have no desire to refrain from torturing animals, even after he adopts the belief that he has a normative reason to do so. ${ }^{6}$ Insofar as Psychopathic Sam, as here characterized, describes a genuine possibility, the upshot is that it is false, as a conceptual claim about desire, that believing one has a normative reason to $\varphi$ is sufficient for desiring to $\varphi$.

Theorists who are inclined towards certain versions of internalism about normative reasons may object that Sam could not have a normative reason to perform an act he has no desire to perform. This objection relies on a version of what Stephen Darwall (1992) calls "existence internalism", according to which an agent could only genuinely have a normative reason to $\varphi$ only if they have a desire to $\varphi$. However, even if existence internalism were true, it would pose no problem for the present argument. This is because my argument does not proceed from the premise that it is true that Sam has a normative reason but rather from the premise that Sam believes that he has a normative reason. Hence, even if existence internalism turns out to be true, it would nevertheless be consistent with Sam believing (albeit falsely) that he has a normative reason to do something he has no desire to do.

It is also possible to object to the preceding argument on what Darwall (1992) would describe as "judgement internalist" grounds. According to certain versions of judgement internalism, believing one has a normative reason to $\varphi$ requires having a desire to $\varphi$. However, this line of objection faces a similar problem to that which faces DAMB; namely, it cannot be part of a general $\mathrm{DAB}$ theory of desires. This is because DAB holds that having normative judgments are a 
necessary condition for having a desire, and so holding that Sam cannot have normative judgements entails that he cannot have desires. Hence, to the extent that the judgement internalist is committed to saying that Sam cannot have normative judgements, then (according to DAB) she is also committed to saying that Sam has no desires. Since it has already been established that Sam does have desires (as illustrated by his desire to torture animals), the attempt to defend DAB on judgement internalist grounds is also moribund. ${ }^{7}$

\section{How Gregory Might Respond}

Gregory considers a pair of putative counterexamples to DAB ${ }^{\mathrm{GR}}$ that are similar to Psychopathic Sam: Smoking Sally and Teething Tabatha. Here are the examples in Gregory's (2017, pp. 207-208) own words:

Smoking Sally: Sally is a smoker. She knows full well she has very good reason to quit: smoking is costly and unhealthy. But she is weak-willed and continues to smoke.

Teething Tabatha: Tabatha knows that she has good reason to go to the dentist: her teeth are in an awful state. But she will quite keenly insist that she doesn't want to go to the dentist—who does?

I agree with Gregory that both Smoking Sally and Teething Tabatha fail to constitute cogent counterexamples to $D A B G$. However, I shall argue that both examples differ from Psychopathic Sam in such a way that Gregory's response to them fails to constitute a plausible response to Psychopathic Sam.

\subsection{The Response to Teething Tabatha}

Let us begin with Teething Tabatha. It is Tabatha's self-report that she does not want to go to the dentist, despite the fact that she knows she has a normative reason to do so, that gives the impression that Teething Tabatha is a counterexample to $\mathrm{DAB}{ }^{\mathrm{GR}}$. In response, Gregory observes that we have good reason to think that Tabatha's claim that she does not want to go to the dentist should not be taken at face value. He elaborates on this point as follows:

One way to see that something puzzling is going on here is to imagine that Tabatha is indeed going to go to the dentist (as she knows she should) but hasn't made her appointment yet. She picks up the phone, gets through to the secretary, and might quite normally say, "Hi, I want to see the dentist today, please." (Ibid, p. 208)

Gregory's elaboration highlights two independent pieces of evidence in support of the conclusion that Tabatha does have a desire to go to the dentist: (i) we can easily imagine her deciding to do so (despite her claim that she does not want to), and (ii) we can easily imagine her reporting that she wants to go to the dentist in other contexts. In the light of (i) and (ii), we have good reason to think that Tabatha does in fact have a desire to go to the dentist. This leaves us with at least two possibilities: either Tabatha is saying something false when she claims she does not want to go to the dentist or her words should not be taken at face value. Gregory favors the second option. Specifically, he claims that "when she insists that she doesn't want to go to the dentist, she really 
means only that she doesn't want the pain that she'll experience there. But this is of course consistent with wanting, all things considered, to go." (Ibid, p. 209)

Gregory's analysis of Teething Tabatha seems plausible. For example, if we were to overhear Tabatha saying to the secretary on the phone that she wants to see the dentist today, we are unlikely to accuse her of being inconsistent because she claimed she did not want to go to the dentist a few minutes earlier. This suggests that we are inclined to take her initial claim that she did not want to go the dentist as elliptical for the much more qualified claim that she does not want to experience the pain associated with going to the dentist. Let us call this the Elliptical Statement Defense. According to the Elliptical Statement Defense, Tabatha's claim that she does not want to go to the dentist should not be taken at face value but is rather elliptical for the claim that she does not want to experience the pain associated with visiting the dentist.

Unfortunately for the defenders of $\mathrm{DAB}^{\mathrm{G} R}$, the Elliptical Statement Defense is ineffective as a reply to Psychopathic Sam. Specifically, we have no reason to think that when Sam claims he has no desire to stop torturing animals, his words are not to be taken at face value. In Teething Tabatha, there is a shared set of assumptions about what it is like to visit a dentist which provides a context for a non-literal interpretation of Tabatha's declaration. The members of Tabatha's target audience are aware of the many health benefits of visiting the dentist and that these benefits typical ground the desire to go to the dentist, despite the unpleasantness such visits tend to involve. Hence, a non-literal reading of Tabatha's words makes sense against the background of these shared assumptions. By contrast, there are not similar kinds of widely shared assumptions about what it is like to torture animals that could be said to ground a non-literal interpretation of Sam's words. Furthermore, the fact that Sam has been diagnosed with psychopathy implies that many of the normal assumptions about human conduct and motivation fail to apply to his statements. In light of this, it is plausible that Sam's claim that he does not desire to refrain from animal torture should be taken at face value.

\subsection{The Response to Smoking Sally}

Next, we turn to Smoking Sally. Gregory describes Sally as weak-willed; she judges that she has most reason not to smoke, but persists in doing so anyway. I must confess that Smoking Sally strikes me as a rather anemic objection to $\mathrm{DAB} G \mathrm{G}$. What makes Sally weak-willed (at least as the notion is standardly conceived) is not that she has no desire to quit smoking, but that her desire to quit is overshadowed by her competing desire to continue doing so. ${ }^{8}$ Hence, it is not clear why one would think that Smoking Sally constitutes an objection to DAB ${ }^{\mathrm{GR}}$. After all, DAB ${ }^{\mathrm{GR}}$ does not claim that if one believes that one has a reason to $\varphi$ then one desires most to $\varphi$. It merely claims that believing one has a normative reason to $\varphi$ is the same as desiring to $\varphi$, which is perfectly consistent with the existence of an even stronger desire not to $\varphi$. As such, Smoking Sally hardly seems to pose a challenge to $\mathrm{DAB}^{\mathrm{GR}}$.

While I do not believe Smoking Sally represents a compelling objection to DAB ${ }^{\mathrm{GR}}$, I also have serious reservations about Gregory's reply to the example. Gregory thinks that Smoking Sally should be explained in exactly the same way as a depressed agent who believes they have a reason to pursue a certain course of action, but feel entirely unmotivated to do so. His strategy for dealing with both cases is to distinguish between desiring to $\varphi$ and being motivated to $\varphi$. He puts the point as follows: 
Once we make this distinction between desiring to do something and being motivated to do it, DAB can also handle numerous other apparent counterexamples, such as people with depression....Clearly, we might believe that we have reason to do something and not be in the least motivated to do it. But this is irrelevant to the truth of DAB...DAB entails only that beliefs about reasons are sufficient for desire, not that beliefs about reasons are sufficient for motivation, as such it is perfectly consistent with weakness of will (Gregory 2017, p. 208).

Gregory's point, then, is that once we concede that desires and motivations can sometimes come apart, we are free to say that in cases of depression, weakness of will, and (one would assume) psychopathy, the agent in question has a desire to do the things they believe they have a normative reason to do. What they lack is the motivation to do it. In short, desiring to $\varphi$ is not sufficient for being motivated to $\varphi$. Call this strategy for responding to Smoking Sally the Impotent Desire Defense.

Unfortunately for the defender of $\mathrm{DAB}^{\mathrm{GR}}$, the Impotent Desire Defense stops short of providing us with any positive reason to think that Sam has a desire to stop torturing animals. Let us grant, if only for the sake of argument, that some desires are entirely motivationally impotent. Of course, it does not follow that all desires are entirely motivationally impotent. Nor does it follow that lacking a motivation to $\varphi$ is sufficient for desiring to $\varphi$. Hence, we cannot conclude from the fact that Sam is unmotivated to stop torturing animals that he has a desire to stop. Indeed, it is common ground between both sides of the present debate that at least some, if not most, desires to $\varphi$ provide some motivation to $\varphi$. It is also common ground between both sides of the debate that in most cases in which an agent is entirely unmotivated to $\varphi$ they also lack a desire to $\varphi$. That is to say, the list of things I am entirely unmotivated to do-e.g., consume live roaches, relocate to a war zone, torture a puppy - is mostly (if not entirely) made up of things I do not desire to do. Moreover, maintaining that in at least some cases in which an agent is unmotivated to $\varphi$, they also lack a desire to $\varphi$ is all we need to get the Psychopathic Sam objection off the ground. The stipulation that Sam does not desire to stop torturing animals is not rooted in the assumption that desiring to $\varphi$ entails being motivated to $\varphi$ and that since Sam is not motivated to $\varphi$, it follows that he does not desire to $\varphi$. Rather, it is rooted in the truism that there are acts we are unmotivated to perform that we also have no desire to perform. In sum, the Psychopathic Sam objection in no way assumes that an agent desires to $\varphi$ only if they are motivated to $\varphi$. Consequently, insisting upon the independence of desire and motivation in no way blunts the force of the objection.

To recap, the Psychopathic Sam objection begins with the stipulation that the agent in question lacks a desire to stop torturing animals and then argues that it is conceivable that such an agent may come to believe that he has a normative reason to stop torturing animals, without undergoing any changes in his desires. Given that possessing moral emotions-like empathy, guilt, and remorse-is not a necessary condition for being completely sure that one has a normative reason to $\varphi$, and given that being completely sure that one has a normative reason to $\varphi$ is sufficient for believing that one has a normative reason to $\varphi$, it follows that possessing moral emotions are not a necessary condition for believing that one has a normative reason to $\varphi$. If this is right, there is no obstacle to affirming that Sam may believe he has a normative reason to $\varphi$ despite his lack of the moral emotions. Moreover, it is conceivable that Sam's lack of moral 
emotions may cause or facilitate his lack of desire to stop torturing animals. The upshot is that Sam appears to represent an agent who is completely sure (i.e., believes) that he has a normative reason to $\varphi$ but who does not desire (owing to his lack of moral emotions) to $\varphi$.

\section{The Temptation Objection}

I now turn my attention to my second objection to DABGR: namely, it implies that an agent is rationally criticizable if she is tempted (in a sense to be specified at present) to do something she believes she has no reason to do. While it may be true that one may be tempted to do something one has absolutely no desire to do (a question about which I wish to remain neutral), it is clear that in at least some cases of being tempted, one has a desire to do what one is tempted to do. For example, in at least some cases in which I am tempted to have a slice of chocolate cake, it is also true that I have a desire to have a slice of chocolate cake. I will refer to all cases in which one is tempted to do something one has a desire to do as a temptation desire. As I shall use the expression, one cannot have a temptation desire to $\varphi$ if one has absolutely no desire to $\varphi$. For example, if I have absolutely no desire to eat a bowl of cottage cheese, then I cannot have a temptation desire to eat a bowl of cottage cheese. Hence, having a temptation desire to $\varphi$ entails having some desire to $\varphi .{ }^{9}$ However, I hold that a temptation desire may be resisted. Hence, having a temptation desire to $\varphi$ does not entail intending to $\varphi$; one may decide to leave one's temptation desire unsatisfied.

With the preceding conception of a temptation desire in mind, let us suppose that I have decided to quit smoking but that I am currently experiencing a temptation desire to have a cigarette. Insofar as I have voluntarily chosen to quit smoking and have not changed my mind, I may be accurately described as desiring not to have a cigarette right now. However, insofar as I am experiencing a temptation desire to have a cigarette, I may also be accurately described as desiring to have a cigarette right now. In short, I have a pair of inconsistent or conflicting desires. However, we would not conclude that I am being irrational simply for having a temptation desire to have a cigarette. Of course, if I acted on the temptation desire, without giving up my intention not to smoke right now, that would be a different story. But the mere experiencing of a temptation desire to smoke right now is not sufficient to make me guilty of irrationality. Call this the Rational Permissibility of Temptation (henceforth, RPT).

In order to be satisfactory, a theory of desire must preserve RPT. At first blush, this is a requirement that $\mathrm{DAB}^{\mathrm{GR}}$ seems able to satisfy. Recall, according to $\mathrm{DAB}^{\mathrm{GR}}$, desiring to $\varphi$ entails the belief that one has a normative reason to $\varphi$. This means that my desire to have a cigarette right now entails the belief that I have a normative reason to have a cigarette right now and that my desire not to have a cigarette right now entails the belief that I have a normative reason not to have a cigarette right now. However, the propositions 'I have a normative reason to have a cigarette right now' and 'I have a normative reason not to have a cigarette right now' are perfectly consistent with each other. Hence, one may believe both propositions without being guilty of irrationality. The upshot is that $\mathrm{DAB}{ }^{\mathrm{GR}}$ is able to preserve RPT, at least in the present case. ${ }^{10}$ Let us call the present strategy for preserving RPT the No Inconsistency Strategy.

While the No Inconsistency Strategy is able to handle cases of temptation desire that involve a conflict between two desires, it is unable to handle cases of temptation desire that involve a 
conflict between a desire and a belief. For example, suppose that after reading John McDowell's "Mind, Value, and Reality" I become convinced that in cases in which $\varphi$ is morally prohibited, all would-be normative reasons for $\varphi$ are silenced so that they fail to constitute normative reasons at all. (Whether or not my belief is true or accurately reflects McDowell's own views will not matter for the purpose of the present argument. All that matters is that it is possible for someone to believe that they cannot have a normative reason to do something they recognize to be morally wrong.) Furthermore, suppose that I believe it would be morally wrong to sabotage a coworker's project out of resentment for her success. Given my belief that one cannot have a normative reason to do something one recognizes to be morally wrong, I infer (and thereby come to believe) that I have no normative reason to sabotage my coworker's project. Despite this fact, I briefly find myself with the temptation desire to sabotage my coworker's project. (Let us also assume that I am horrified by very thought of sabotaging my coworker's project and that resolve not to give in to said temptation desire.)

According to $\mathrm{DAB}^{\mathrm{GR}}$, insofar as I desire to sabotage my coworker's project, I believe that I have a normative reason to sabotage my coworker's project. However, by stipulation of the example, insofar as I believe it is morally wrong to sabotage my coworker's project, I also believe that I have no normative reason to sabotage my coworker's project. It follows that I have inconsistent beliefs and I am therefore guilty of irrationality. The upshot is that according to $\mathrm{DAB}^{\mathrm{GR}}$, someone who happens to believe that they have no normative reason to $\varphi$, but who nevertheless finds themselves with a temptation desire to $\varphi$, is ipso facto guilty of irrationality. But according to RPT, my merely having a temptation desire to sabotage my coworker's project should not be sufficient to make me guilty of irrationality. Hence, $\mathrm{DAB}{ }^{\mathrm{GR}}$ is unable to preserve RPT in cases in which one has a temptation desire to do something one believes one has no normative reason to do.

My diagnosis of where $\mathrm{DAB}^{\mathrm{GR}}$ goes wrong is that it attempts to preserve the intuition that one is not rationally criticizable for having conflicting desires by simply denying that it is possible for two desires to have genuinely inconsistent propositional contents. Recall, DABGR claims that in cases in which I desire that I not have a cigarette right now and also desires that I have a cigarette right now, I have a pair of beliefs with perfectly consistent contents: the belief that I have a normative reason to have a cigarette right now and the belief that I have a normative reason not to have a cigarette right now. Moreover, since a desire is never identical to the belief that I have no normative reasons, there can never arise a situation in which a pair of desires turn out to be identical to a pair of inconsistent beliefs. Hence, according to $\mathrm{DAB} \mathrm{BR}^{\mathrm{R}}$, the reason it is rationally permissible to have conflicting desires is because conflicting desires turn out to be perfectly consistent beliefs. What this strategy for preserving RPT overlooks is that even if it is not possible for a pair of desires to be identical to a pair of inconsistent beliefs, it is still possible for a desire to be identical to a belief that is inconsistent with another one of an agent's beliefs. In such cases, the need to preserve RPT arises anew. However, the No Inconsistency Strategy is unable to avoid the inconsistency between an agent's beliefs in such cases. The result is that DAB ${ }^{G R}$ entails that an agent who has a desire and a belief with inconsistent propositional contents thereby has a pair of inconsistent beliefs, and is therefore guilty of irrationality. In order to avoid this conclusion, we must reject the claim that desiring to $\varphi$ entails believing that one has a normative reason to $\varphi$. 
Significantly, the temptation objection may be employed to establish the falsity of both DABGR and $\mathrm{DAB}^{\mathrm{GG}}$. This is because the criticism is based on general principles concerning the norms governing belief and desire. Any theory of desire, if it is to be satisfactory, will need to preserve RPT. However, whatever one takes the propositional content of the desire to $\varphi$ to be-whether it is the proposition $\varphi$ is good or the proposition that one has a reason to $\varphi$-it will be possible to construct a case in which an agent has a belief whose content is inconsistent with the propositional content of said desire. In all such cases, the need to preserve RPT will arise anew. For example, if I held that the desire to $\varphi$ is identical to the belief that $\varphi$ is good or worthwhile, then it will be possible to construct a case in which an agent believes $\varphi$ is completely devoid of goodness or worth but in which the agent finds themselves with a temptation desire to $\varphi$. According to RPT, the mere fact that the agent has a temptation desire to $\varphi$ should not be enough to make them guilty of irrationality in such cases. However, if we assume that a desire is identical to the belief that $\varphi$ is good or worthwhile, then the agent in question would be guilty of irrationality for having inconsistent beliefs. Thus, the temptation objection is equally effective as an objection to DAB ${ }^{\mathrm{GR}}$ and $\mathrm{DAB}{ }^{\mathrm{GG}}$.

\section{Conclusion}

In this paper, I have advance two independent objections to DABGr: the psychopathy and temptation objections. The first objection offers a counterexample to DABGR by presenting a putative case in which an agent, Sam, believes he has a normative reason to refrain from torturing animals but does not have a desire to refrain. The second objection is directed at both DABGR and $\mathrm{DAB}^{\mathrm{GG}}$. Whether one identifies a desire to $\varphi$ with the belief that one has a normative reason to $\varphi$ or the belief that $\varphi$ is good, it will be possible to construct a case in which an agent desires $\varphi$ but believes that they have no normative reason to $\varphi$ or that $\varphi$ is not good, respectively. In all such cases, it would follow that the agent in question is guilty of irrationality for having inconsistent beliefs. However, this runs afoul of the truism that one is not guilty of irrationality for simply experiencing a temptation desire. In light of these problems, I conclude that the theses that the desire to $\varphi$ is identical to the belief that one has a normative reason to $\varphi$ or the belief that $\varphi$ is good should be rejected.

Acknowledgements I will like to thank Lauren Ashwell, Keira McNett, Usha Nathan, and the audience members at the Southern Society for Philosophy and Psychology for their valuable feedback on earlier versions of this paper. 


\section{References}

Archer, A. (2016). Do Desires Provide Reasons? An Argument Against the Cognitivist Strategy. Philosophical Studies 173 (8): 2011-2027.

Darwall, S. (1992). Internalism and Agency. Philosophical Perspectives 6: 155-174.

Davidson, D., (1970). How Is Weakness of the Will Possible? in Davidson 1980: 21-42.

Davidson, D. (1980). Essays on Actions and Events. (Oxford: Clarendon Press).

Davidson, D. (1982). Paradoxes of Irrationality, in Davidson 2004: 169-187.

Davidson, D. (2004). Problems of Rationality, (Oxford: Clarendon Press).

Frontiers. (2013). Neurological basis for lack of empathy in psychopaths. Science Daily. www.sciencedaily.com/releases/2013/09/130924174331.htm (accessed June 6, 2018).

Gregory, A. (2013). The Guise of Reasons. American Philosophical Quarterly 50 (1): 63-72

Gregory, A. (2017). Might Desires Be Beliefs About Normative Reasons? In J. Deonna \& F. Lauria (eds.), The Nature of Desire. (Oxford: Oxford University Press): 201-217.

Gregory, A. (2018). Why Do Desires Rationalize Actions? Ergo 5 (40): 1061-1081.

Massin, O. (2017). Desires, Values and Norms. In J. Deonna \& F. Lauria (eds.), The Nature of Desire. (Oxford: Oxford University Press): 165-200.

McAleer, K. (2010). Sociopathy vs. Psychopathy. Psych Central. Retrieved on May 21, 2018, from https://blogs.psychcentral.com/forensic-focus/2010/07/sociopathy-vs-psychopathy/

Lauria, F. (2017). The "Guise of the Ought-to-Be": A Deontic View of the Intentionality of Desire. In J. Deonna \& F. Lauria (eds.), The Nature of Desire. (Oxford: Oxford University Press): 139-164.

Oddie, G. (2005). Value, Reality, and Desire. Oxford, UK: Oxford University Press.

Stampe, D. (1987). The Authority of Desire. Philosophical Review 96: 335-381.

Tenenbaum, S. (2003). Accidie, Evaluation, and Motivation. In Christine Tappolet \& Sarah Stroud (eds.), Weakness of Will and Practical Irrationality. (Oxford: Clarendon Press), pp. 147-171.

Tenenbaum, S. (2007). Appearances of the Good. (Cambridge, UK: Cambridge University Press).

Walsh, A., \& Wu, H.H. (2008). Differentiating antisocial personality disorder, psychopathy, and sociopathy: Evolutionary, genetic, neurological, and sociological considerations. Criminal Justice Studies, 2: 135-152. 


\footnotetext{
${ }^{1}$ See Gregory (2017) for a sustained defense of DAB.

${ }^{2}$ Theorists who have defended some version of the guise of reasons account include: Gregory $(2013,2017,2018)$, Massin (2017), and Lauria (2017).

${ }^{3}$ For a concise statement of my primary motivation for preferring DAA over DAB, see Archer (2016: pp. 20122016).

${ }^{4}$ The present argument does not presuppose that evidence is the only source of justification for a belief, only that it is one possible source of justification.

${ }^{5}$ The shift from saying that Sam believes animal torture to be morally prohibited to saying that Sam believes that animal torture is morally frowned upon comports with a common analysis of the amoral agent, according to which such an agent takes moral pronouncements to reflect the moral assessments of other individuals or society in general as opposed to their own personal assessment of an actions moral standing. While I am inclined to disagree with this analysis of the amoral agent, it is one that the current line of argument is able to accommodate.

${ }^{6}$ There are of course views according to which one may only have a normative reason to do something one desires to do. However, this is not a view Sam need have. Hence, even if internalism turned out to be true, it may also be true that Sam believes (in this case, falsely) that he has a normative reason to refrain from torturing animals. In sum, my argument proceeds from the premise that Sam has a certain belief, not from the premise that the belief in question is true.

${ }^{7}$ It should be emphasized that since most judgement internalists are not also advocates of DAB, the immediately preceding point is not meant as a criticism of judgement internalism, per se. It is only a criticism of the combination of a certain version of judgement internalism with DAB.

${ }^{8}$ Weakness of will is standardly conceived of as involving conflicting desires. For the locus classicus of the standard conception of weakness of will, see Davidson (1970, 1982). Gregory's treatment of weakness of will seems better suited for cases of accidie, depression, or dejection. For a particularly helpful discussion of accidie, see: Tenenbaum (2003).

${ }^{9}$ The present restriction on my use of the word temptation is intended to clarify how I will be using the term in the discussion that follows. I do not claim that this is the only or even the best way of conceiving of temptation.

${ }^{10}$ A similar strategy for preserving RPT is open to defenders of the guise of the good formulation of DAB. In that case, the relevant propositions will be: 'It would be good to have a cigarette right now' and 'It would be good not to have a cigarette right now.' Since it is possible for both $\mathbf{P}$ and $\neg \mathbf{P}$ to be good or worthwhile, these are not inconsistent propositions.
} 